
\title{
3 Research Soure \\ First Report of SYNE1 Arthrogryposis Multiplex Congenita From Saudi Arabia With a Novel Mutation: A Case Report
}

Naglaa Kamal ( $\square$ nagla.kamal@kasralainy.edu.eg )

Cairo University Kasr Alainy Faculty of Medicine https://orcid.org/0000-0002-8535-3838

Alaaeddin Alzeky

Al-Hada Military Hospital: Al Hada Military Hospital

Maher R Omair

Al-Hada Military Hospital: Al Hada Military Hospital

Ruwayd Attar

Al-Hada Military Hospital: Al Hada Military Hospital

Abdullah Alotaibi

Al-Hada Military Hospital: Al Hada Military Hospital

Abdullah safar

Al-Hada Military Hospital: Al Hada Military Hospital

\section{Case report}

Keywords: SYNE1, Arthrogryposis Multiplex Congenita, Saudi Arabia, novel

Posted Date: November 18th, 2021

DOI: https://doi.org/10.21203/rs.3.rs-1053130/v1

License: (1) This work is licensed under a Creative Commons Attribution 4.0 International License.

Read Full License 


\section{Abstract}

Introduction: Arthrogryposis multiplex congenita (AMC), is a rare congenital condition characterized by multiple joint contractures often affecting both arms and legs which start prior to birth.

Patient concern: The pediatrician attending delivery noticed the baby being dysmorphic with generalized hypotonia and multiple joint contractures at birth with antenatal history of reduced fetal movement. The patient was admitted to the neonatal intensive care unit for strict observation and further work up.

Diagnosis: Whole Exome Sequencing was performed and identified the novel homozygous variant in the synaptic nuclear envelope protein1 [SYNE1] gene.

Intervention: Multidisciplinary team were involved in the management plan, supportive care was the mainstay of treatment.

Outcomes: Due to feeding difficulties and on and off requirement of oxygen support, the patient remained hospitalized for a long period then was discharged home on supplemental oxygen and gastrostomy tube feeding.

Conclusions: AMC3 should be suspected in patients with decreased fetal movements, dysmorphic features, hypotonia, and arthrogryposis. Molecular testing of the SYNE1 gene confirms diagnosis.

\section{Introduction}

Arthrogryposis multiplex congenita (AMC), describe a variety of unprogressive skeletal defects with joint contractures found throughout the body, arms and legs are more commonly affected, presenting at birth. ${ }^{1}$

Arthrogryposis is a rare condition. prevalence is one in 3000 in general population ${ }^{2}$ it is less common in European population, occurring in 1 out of every $11000-12000$ live births $^{3}$.

There is no single cause for AMC. Decreased fetal movement in utero is one known factor, which can occur due to variety of reasons, including environmental factors (i.e. maternal illness, limited space), gene mutation (autosomal dominant, autosomal recessive, $X$-linked), chromosomal abnormalities and various syndromes ${ }^{4}$

Myogenic-type arthrogryposis multiplex congenita-3 (AMC3) is an autosomal recessive disorder characterized by decreased fetal movements, hypotonia, variable skeletal defects, including clubfoot and scoliosis, and delayed motor milestones with difficulty walking ${ }^{5}$

SYNE1 gene is found in many tissues, encodes nesprin-1, a member of the spectrin family of structural proteins that link the nuclear plasma membrane to the actin cytoskeleton. Mutations in this gene have been associated with multiple congenital conditions, one of them is Myogenic-type AMC3. ${ }^{5}$ 
The present report describes a Saudi newborn baby boy with dysmorphic feature, hypotonia and multiple joint contractures, in whom Whole Exome Sequencing identified a novel homozygous variant c.234153799C G p.(?) in the SYNE1 gene (OMIM:608441).

\section{Case Report}

SA is 6-month-old Saudi male who was born to a healthy first-degree relatives Saudi cousins, with uneventful perinatal history, and negative family history of neuromuscular disease. He was delivered at term by elective cesarean section due to breech presentation, to a 30-year-old G4P3 mother.

His Antenatal ultrasound scan showed reduced fetal movements. Apgar score was 5 and 7 at 1 and 5 minutes respectively. Birth weight was $2595 \mathrm{~g}$ (50th centile) and occipitofrontal circumference was $37 \mathrm{~cm}$ (50th centile).

He was admitted to the neonatal intensive care with respiratory distress, requiring intubation and positive pressure ventilation.

His examination revealed subtle dysmorphism in form of long narrow face, hirsutism long philtrum, depressed nasal bridge, flat occiput, large ears along with generalized muscle wasting added to arthrogryposis multiplex in the upper \& lower limbs, involving interphalangeal joint, metatarsophalangeal joint, thoraco-lumbar scoliosis, bilateral knee dislocation, bilateral club foot, clenched hand and overlapping fingers (Figures 1a-d).

Neurological examination showed generalized hypotonia and absent deep tendon reflexes. Brain magnetic resonance imaging showed no abnormal findings.

Echocardiogram showed small mid-muscular ventricular septal defect, and small patent ductus arteriosus with otherwise normal cardiac structure and function.

Abdominal examination showed no organomegaly, normal looking genitalia with bilateral undescended testis. His other body system review was unremarkable.

Laboratory investigations revealed normal complete blood count, renal and hepatic functions, normal electrolytes and normal creatinine kinase as well as metabolic screening. Karyotyping revealed a normal $46, X Y$ karyotype.

Due to feeding difficulties and intermittent requirement of oxygen support, he was discharged on gastrostomy tube feeding and home oxygen.

\section{Mutation identification:}

Molecular genetic analysis of whole exome sequencing was done (Figure 2). 
Analysis: The coding exons of more than 20.000 genes of the patient DNA were enriched and sequenced. Filtering of the exome data targeted recessive, X-linked and dominantly inherited diseases

Result: Variant with significant phenotypic overlap in the proband was identified (Table 1).

Table 1

Molecular genetic identification

\begin{tabular}{|c|c|c|c|c|c|}
\hline Classification & $\begin{array}{l}\text { MAF } \\
\text { GenomAD } \\
{[\%]}\end{array}$ & Zygosity & Variant & $\begin{array}{l}\text { Phenotype MIM } \\
\text { number (Mode } \\
\text { of Inheritance) }\end{array}$ & $\begin{array}{l}\text { Gene } \\
\text { (isoform) }\end{array}$ \\
\hline $\begin{array}{l}\text { Variant of } \\
\text { Uncertain } \\
\text { Significance }\end{array}$ & 0 & Hom. & $\begin{array}{l}\text { c. } 23415- \\
3799 C>G \\
\text { p.(?) } \\
\text { chr6.152489259 }\end{array}$ & $\begin{array}{l}618484(A R) \\
612998(A D) \\
610743(A R)\end{array}$ & $\begin{array}{l}\text { SYNE1 } \\
\text { (NM_033071.3) }\end{array}$ \\
\hline
\end{tabular}

Interpretation: WES identified the homozygous variant c.23415-3799C>G p.(?) in the SYNE1 gene (OMIM: 608441). This is a deep intronic variant with unclear consequence on protein sequence. However, based on another isoform of the gene (NM_001347702.1) the variant nomenclature is c.81C>G p.(Cys27Trp) which leads to an amino acid exchange.

Seven out of 20 bioinformatic in silico programs predict a pathogenic effect for this variant. To the best of our knowledge the variant has not been described in the literature so far (HGMD 2020.2).

Allele frequency of this variant in the general population has not been documented and this is the first time to be reported. Considering the available information, the variant is classified as variant of uncertain significance.

Pathogenic variants in the SYNE1 gene cause autosomal recessive myogenic arthrogryposis multiplex congenital type 3 (AMC3; OMIM: 618484) among others. AMC3 is characterized by decreased fetal movements, hypotonia, variable skeletal defects, including clubfoot and scoliosis, contractures, and delayed motor milestones with difficulty walking.

\section{Considering the homozygous variant of uncertain significance in the SYNE1 gene, a genetic diagnosis of myogenic arthrogryposis multiplex congenita type 3 for the patient is possible.}

For further interpretation of the results and to improve variant classification, segregation analysis of the identified variant in the parents and further affected and unaffected family members was done. It revealed that both parents and 1 apparently healthy sibling were carrying the same mutation in heterozygous status. Two other siblings were normal. 


\section{Secondary findings (reported according to ACMG guidelines):}

No pathogenic or likely pathogenic variants were detected in the genes for which incidental findings are reported based on the ACMG guidelines.

\section{Discussion}

The term arthrogryposis, or AMC, refers to a group of nonprogressive disorders characterized by multiple joint contractures discovered at birth in the body. ${ }^{1}$

Review of the Saudi literature, arthrogryposis was occasionally described but with different gene mutation and clinical syndromes. The mutation identified in this paper is a novel mutation which was not reported before Saudi Arabia and has not been described in the literature so far.

Reviewing English literature revealed only five reported cases with variable mutations in SYNE1 gene, with similar clinical manifestation. 5,6,7

Our patient is the sixth patient worldwide identified with an AMC-causing SYNE1 mutation.

Other than AMC; all patients shared some clinical findings including reduced fetal movements, absence of polyhydramnios, no noticeable intrauterine growth retardation, and absence of associated malformations (Table 2). They have borderline to average intellectual growth and motor development is slightly delayed without creatinine kinase elevation (Table 2). 
Table 2

Summary of previously reported cases of AMC 3

\begin{tabular}{|c|c|c|c|c|}
\hline Patient ID & Patient 1 & Patient 2 & Patient 3 & Patient 4 \\
\hline sex & male & male & Female & Male \\
\hline $\begin{array}{l}\text { Antenatal reduce } \\
\text { fetal movements }\end{array}$ & yes & yes & Yes & Yes \\
\hline Polyhydramnios & No & No? & No & No \\
\hline Inheritance & AR & AR & AR & AR \\
\hline Dysmorphic feature & yes & No & No & No \\
\hline $\begin{array}{l}\text { Skeletal } \\
\text {-spine }\end{array}$ & $\begin{array}{l}\text { severe } \\
\text { scoliosis }\end{array}$ & severe kyphoscoliosis & $\begin{array}{l}\text { Severe } \\
\text { scoliosis }\end{array}$ & - \\
\hline - clenched hands & Yes & - & - & $\begin{array}{l}\text { Adducted } \\
\text { thumb }\end{array}$ \\
\hline - club foot & Yes & Yes & Yes & Yes \\
\hline - joint dislocation & Yes & - & - & - \\
\hline - Arthrogryposis & Yes & Yes & Yes & Yes \\
\hline $\begin{array}{l}\text { Undescended } \\
\text { testicles }\end{array}$ & Yes & - & - & yes \\
\hline $\begin{array}{l}\text { Neurologic: } \\
\text { - Microcephaly }\end{array}$ & No & No & No & No \\
\hline - hypotonia & Yes & Yes & Yes & Yes \\
\hline - reflexes & Reduced & - & Absent & Reduced \\
\hline - Epilepsy & No & No & No & \\
\hline Intelligence & Low & Normal & Normal & Low \\
\hline MRI brain & Normal & - & - & \\
\hline EMG & - & Normal & Normal & Normal \\
\hline CK level & Normal & Normal & Normal & Normal \\
\hline disease course & Progressive & Progressive & Progressive & Progressive \\
\hline Outcomes & Alive & $\begin{array}{l}\text { Died at age of } 22 \text { years due to } \\
\text { pneumonia and sepsis }\end{array}$ & Alive & Alive \\
\hline
\end{tabular}

The condition was progressive in one family of sib pairs that were unable to walk at 12 years of age and developed severe scoliosis, leading to death from pneumonia in one patient at 22 years of age. ${ }^{7}$ There is 
no indication of cerebellar disease in these patients. While the progression of the disease is unpredictable, as five out of six living patients are younger than 20 years.

Two reported sibs were reported in one paper with limited clinical details. ${ }^{6}$

\section{Conclusions}

High index of suspicion is needed to diagnose AMC3 in patients with decreased fetal movements, dysmorphic features, hypotonia, and arthrogryposis. Molecular genetic analysis of the SYNE1 gene confirms diagnosis.

\section{Abbreviations}

Arthrogryposis multiplex congenita (AMC)

Synaptic nuclear envelope protein1 [SYNE1]

Myogenic arthrogryposis multiplex congenital type 3 (AMC3)

\section{Declarations}

- Ethical Approval and Consent to participate: the study was approved by the research and ethical committee of the participating hospitals. All parents of enrolled children signed written informed consents for participation of their children in the current study.

- 'Written informed consent was obtained from the patient's legal guardian for the publication of any potentially identifiable images or data included in this article.

- Consent for publication: All parents of enrolled children signed written informed consents for publication the current study.

- Availability of data and materials: all data and materials related to the study are included in the current manuscript.

- Competing interests: all authors declare no competing interests related to the study

- Funding: No funds were available for the current research

\section{Authors' contributions:}

$\mathrm{NK}, \mathrm{AE}, \mathrm{MO}$ : set the idea of the study and designed the study

AE, MO: Diagnosed the patient \& critically analyzed the data

NK, RA, AA, AS: reviewed literature \& drafted the manuscript

RA, AA, AS: collected patient's data 
All authors reviewed and approved the manuscript for final publication

\section{References}

1. Taricco LD, Aoki SS. Rehabilitation of an adult patient with arthrogryposis multiplex congenita treated with an external fixator. Am J Phys Med Rehabil. 2009; 88(5):431-4.

2. Bamshad, M, Van Heest AE, Pleasure D. "Arthrogryposis: A Review and Update". J Bone Joint Surg Am 2009; 91(Suppl 4): 40-6.

3. Miller M, Dobbs M. Congenital Vertical Talus. J Am Acad Orthop Surg 2015; 23 (10): 604-11.

4. Bevan W, Hall J, Bamshad M, Staheli L, Jaffe K, Song, K. Arthrogryposis Multiplex Congenita (Amyoplasia). J Pediatr Orthop 2007; 27 (5): 594-600.

5. Baumann M, Steichen-Gersdorf E, Krabichler B, Petersen B-S, Weber U, Schmidt WM, Zschocke J, Muller T, Bittner RE, Janecke AR. Homozygous SYNE1 mutation causes congenital onset of muscular weakness with distal arthrogryposis: a genotype-phenotype correlation. Europ J Hum Genet 2017; 25: 262-6.

6. Laquerriere A, Maluenda J, Camus A, Fontenas L, Dieterich K, Nolent F, Zhou J, Monnier N, Latour P, Gentil D, Heron D, Desguerres I, and 48 others. Mutations in CNTNAP1 and ADCY6 are responsible for severe arthrogryposis multiplex congenita with axoglial defects. Hum Molec Genet 2014; 23: 227989.

7. Attali R, Warwar N, Israel A, Gurt I, McNally E, Puckelwartz M, Glick B, Nevo Y, Ben-Neriah Z, Melki J. Mutation of SYNE-1, encoding an essential component of the nuclear lamina, is responsible for autosomal recessive arthrogryposis. Hum Molec Genet 2009; 18: 3462-9.

\section{Figures}



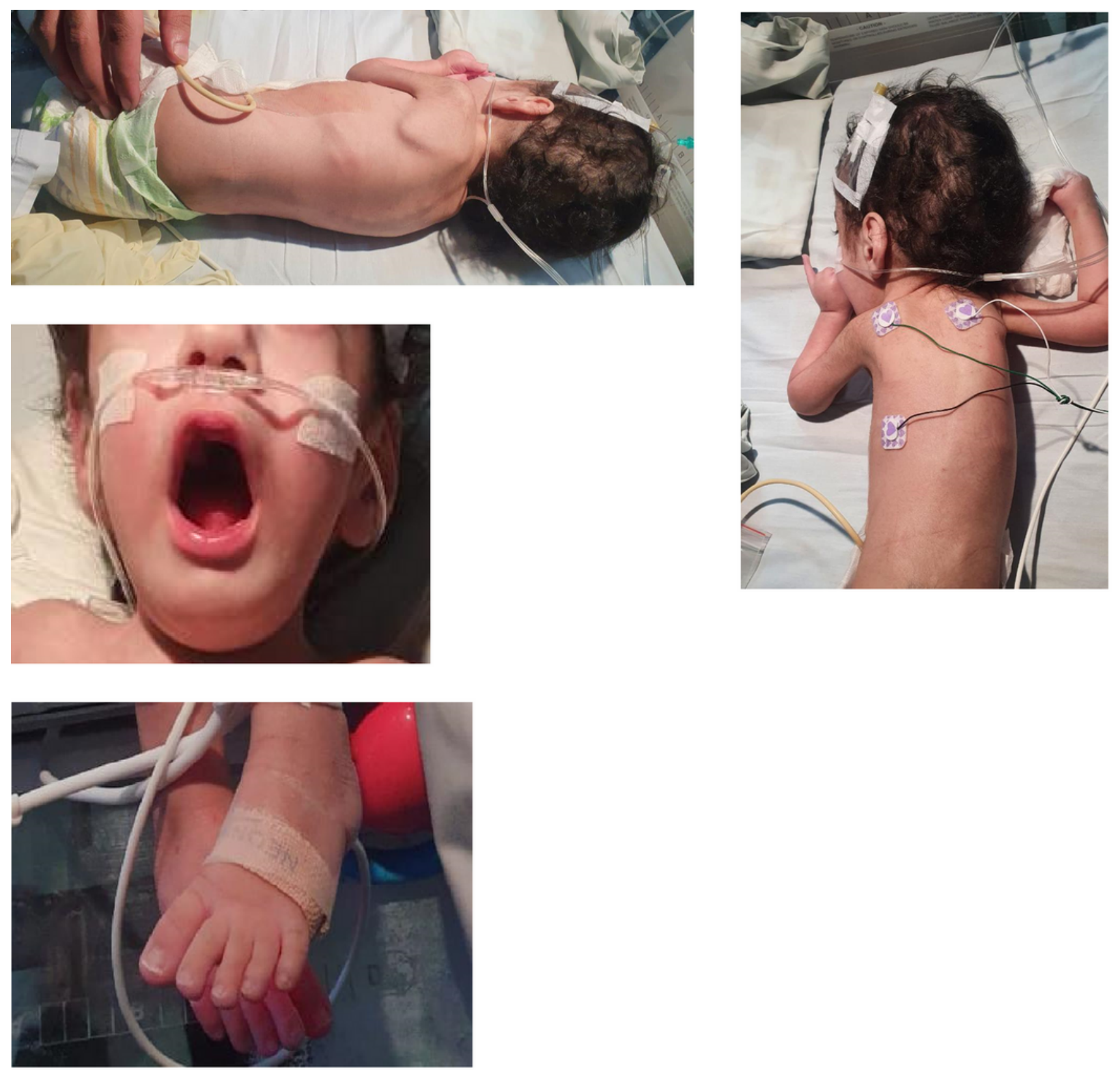

\section{Figure 1}

a: Winging scapula b: Myopathic facies; elongated face, chest deformity, pictus excavatum, knee joint contracture c: Long slender toes d: Kyphoscoliosis 


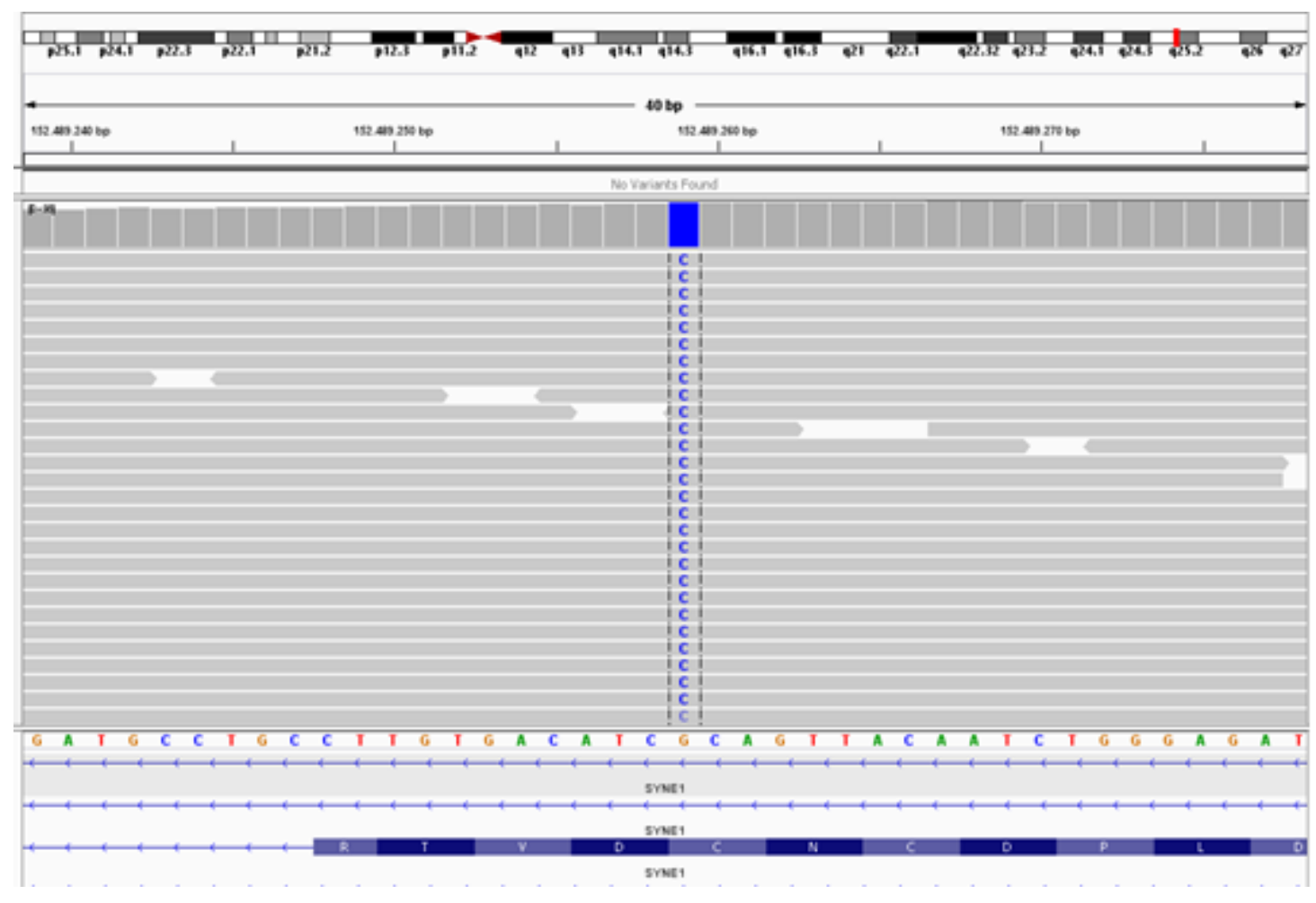

Figure 2

Chromatogram of whole exome sequencing of the patient 